Ref: 115

GAMESEXPAPER

\title{
The social context of school playground games: sex and ethnic differences, and changes over time after entry to junior school
}

\author{
Peter Blatchford*, Ed Baines* and Anthony Pellegrini** \\ *Institute of Education, University of London \\ **Dept of Educational Psychology, University of Minnesota
}

Revised August 2002

Published 2003 in British J of Developmental Psychology, 21,481-505

Address for correspondence to Peter Blatchford, Psychology \& Special Needs, Institute of Education, University of London, 25 Woburn Square, London WC1H 0AA, UK. Email:

P.Blatchford@ioe.ac.uk 


\title{
The social context of school playground games: sex and ethnic differences, and changes over time after entry to junior school
}

\begin{abstract}
This short term longitudinal study examined activities at recess and peer relations. Interest was in changes over the school year, and the sex and ethnic mix of groups. Data came from systematic observations of 129 pupils (61 boys and 68 girls) aged 7-8 years. Results showed that peer interaction dominated recess. Ball games increased over the year, and chasing games decreased. Aggression was most common during vigorous play and conversation, but not ball games. Cleavage in boys' and girls' play and activity was common but not inevitable. Mixed sex play was not supported by particular game types. Boys' game networks were larger than those of girls but there were no sex differences in active networks. There was little ethnic group segregation on playgrounds, and games became more integrated with time. Results indicate that playground activities can have a positive role in social relations between different ethnic groups.
\end{abstract}

Keywords: playground games; play; peer relations; recess 


\section{The social context of school playground games: gender and ethnic differences, and changes over time after entry to junior school}

\section{Introduction}

If one can conceive of settings during childhood on a scale of 'openness', varying in the degree to which children can interact relatively freely with each other away from adult control, then recess (or breaktime or playtime as it is termed in the UK) is one of the main 'open' settings with more degrees of freedom and more opportunities to interact with peers. Given that school is mandatory, draws many children from a locality, and that recess usually takes up a sizeable part of the school day and that children at primary level, weather permitting, usually go outside at recess (Blatchford \& Sumpner, 1998), it is an excellent resource for studying the games of a relatively large and often diverse sample of children, in an 'authentic' setting. By stressing children's interactions on the school playground we do not mean to minimise the role of other venues of peer interaction, for example, in classrooms, out of school and in the home. However, there is evidence that opportunities for independent activities and interactions with peers outside the home are diminishing (Hillman, 1993), and the school playground is a main venue for peer interaction and meeting friends (Blatchford, 1998). Recess durations tend to be shorter in the USA, but in both the U.K. and the USA recess at primary level is often taken up with play and games (Boulton, 1992; Pellegrini \& Smith, 1998).

This paper starts from the premise that there are important connections between playground activities during school recess and peer social relations and that close observation of everyday activities on playgrounds can reveal a good deal about children's social capabilities and development. SuttonSmith has shown ways in which children's playground play and games and their peer relations are connected. He argues (Sutton-Smith, 1982) that playground culture is expressed through what he calls the 'performances' that children engage in. He has argued that: "the most important thing to know about peer culture is what is going on there. That is, that we might learn more of the structure and more of the 


\section{The Social context of school playground games}

function if we first studied what the action is (that is) the performances that are central to children..." (p68). A main 'performance' at school, in the case of primary school pupils, involves games and play (Boulton, 1992).

Study of the nature and development of children's playground games has been an area of disparate, but limited, research interest. While folklorists (Opie \& Opie, 1969) and ethnographers (Sluckin, 1981) have described children's games in the communities and schools, our knowledge of the psychological development of games is limited. Given that theory (e.g. Piaget, 1965) suggests that games have important implications for children's social and cognitive development, it is perhaps surprising that playground games have not received much empirical attention from developmental or educational psychologists. More generally, one facet of children's adjustment to school is the development of successful social relations with peers, and a main site for the everyday encounters that reflect and support these relations is the school playground. There is some agreement that recess provides opportunities, in the context of games, for children to acquire informally a range of social skills with their peers (Blatchford, 1998, Sluckin, 1981). There are also suggestions that games can mediate social relations and adjustment to school, e.g. by acting as a 'scaffold' to initially unacquainted or social unsophisticated children (Pellegrini \& Blatchford, 2002).

Blatchford (1996) charted long term developmental changes in playground activities over the primary and secondary school years. Pupils' reported playground games and activities at 11 years were dominated by active games. The most popular were ball games and chasing games, and the most popular game of all was football (i.e. soccer); this was played by boys more than girls ( $84 \%$ of boys, $36 \%$ of girls). Other ball games such as netball, basketball, and cricket were played by a third of children. Chasing games were defined in the same way as the Opies, that is, games in which a player tries to touch others who are running freely in a prescribed area. The most common chasing game by far was the basic game of 'it', 'had' or 'he' (46\% of children). Seeking games (17\%), catching games $(16 \%)$, racing games $(12 \%)$ and skipping games (9\% with a rope, $6 \%$ with elastic) were also noted. In 


\section{The Social context of school playground games}

response to a separate question, concerning what else they did at recess, talking to friends (48\%), walking and hanging around (32\%) and just sitting down (28\%) were the most commonly cited activities. Results indicated that a main change with age from 11 to 16 years in recess activities was from active games such as football, chasing and catching at the primary stage, to talking and socialising with friends by the end of the secondary stage. But this study was unable to say much about shorter term changes or games of younger children. The age around 6-8 years is likely to be particularly interesting for study because games are a prevalent part of peer interaction. Yet, according to Parker \& Gottman (1989), this is about the time that the dominance of play in early childhood is joined by the emergence of friendships and social conversation typical of middle childhood. Following suggestions that playground activities can play a role in the development of peer relations in children who may be previously unacquainted (Pellegrini and Blatchford, 2002), interest was in developments over the first year after entry into the junior stage of primary education, that is, Key Stage 2 (the year in which children become 8 years).

We argue that little is known about three main aspects of playground games. In this exploratory paper, our aim is to provide descriptive information on three main areas: first, the prevalence of particular types of games and behaviours on playgrounds and changes over the school year, second, sex differences in the frequency of involvement in games and the extent of mixed sex versus same sex groups over the year, and, third, the degree to which game groups were ethnically mixed and whether this changed over the year. We also examine the age mix of playground game groups.

Frequency of playground games and behaviours and changes over the school year

To date there is little descriptive data on games, in contrast with other aspects of children's play (e.g., Fein, 1981; Pellegrini \& Smith, 1998; Rubin, Fein \& Vandenberg, 1983). As said above, in previous research long term developmental changes in recess activities have been charted (Blatchford, 1996), but interest here was in changes in playground games and behaviour in the short term, and in younger children after entry to junior school. Our first aim was therefore to collect information on the 


\section{The Social context of school playground games}

frequency of games and social activities of children over this period in order to provide a more complete picture of developmental trends of play and games to that stemming from theoretically derived accounts (e.g., Piaget, 1965), and to enable comparison with other research.

There were several specific areas of interest. First, with regard to general levels of sociability on the playground, it was expected that with familiarity and confidence in a new setting there would be more social interaction overall and fewer occasions when children were on their own or playing alongside but not with others. Drawing on Parten's (1932, 1933a, 1993b) well known categories, it was expected that there would be more social but less solitary or parallel activity over the year. For similar reasons it was anticipated that the overall amount of engagement in games on the playground would increase but that unoccupied behaviour and times when children just watched others would decline. It was also expected that signs of difficulties with the playground setting and peers, expressed through, for example, distress and crying, would decrease over the year. Predictions concerning aggressive, argumentative, and teasing and taunting behaviour and incidents when children are corrected or disciplined by adults were more difficult to make. It might be expected that these will increase with growing familiarity between peers, and increased activity levels, but they might also decrease as social competence and behaviour expected in school improves.

Second, interest was in the prevalence of, and changes over the year in, different kinds of games. Contrary predictions can be made. It might be predicted that games involving knowledge of rules will increase as the year progresses. It requires time and maturation for children to learn the rules of games played a school, and connections between cognitive development and games with rules are well established (Garvey, 1978). Once these rules are learned, children must learn to use them to initiate and maintain games. Correspondingly, they must also learn to subordinate their perspectives to those of their peers. This should mean that ball games like football, which require knowledge of rules, and social and physical skills, should increase over the year. Other games, such as chasing, seeking and catching games can also involve complex rules (see Opie \& Opie, 1969) and can be expected to 


\section{The Social context of school playground games}

increase over time. On the other hand, Blatchford (1998) indicated that 'traditional' chasing, catching and seeking games, such as 'forty forty' and 'What's the time Mr Wolf' declined over the year, perhaps as a result of peer pressure, or inherent limitations in the game itself. It might therefore be predicted that chasing, seeking and catching games would decline over the year. If games do increase over the year, it might be predicted that play activities, like vigorous play and fantasy play, would become of less interest, and therefore decline over the year. But there are few descriptive studies that have tested these suggestions and this study was designed to provide empirical information on changes in games over the school year. It may be that some games become less popular, and hence decline with time, because there are more disputes or aggression, and in this study the connections between game types and behaviour was examined.

Third, we were interested in changes in the size of the groups within which children played games. Again, different predictions concerning changes over time could be made. It might be expected that the number of children involved would increase as involvement in play and games with rules increases. Yet Blatchford (1998) indicated that after an initial stage when games served as a 'scaffold' for social exploration, over time, and as friendship groups developed and stabilised, there could be progressively fewer opportunities for meeting others outside the group. This might be expected to mean fewer children over time involved in games. On logical grounds and on the basis of pilot observations on playgrounds, conducted for the present study, it was considered important to distinguish between two types of groups on playgrounds, first, the number of children who were actively interacting at one time, in terms of talking or being physically engaged, and, second, the number of children involved in the game, which could be a larger unit. These two types of groups were called 'active' and 'game' networks respectively. Early observations indicated that in some games, for example football, a large group of children could be involved in the game, but there was a smaller group with whom any given children would be actively engaged. 


\section{The Social context of school playground games}

\section{$\underline{\text { Sex differences in games }}$}

A second aim of this study involved the examination of sex differences in playground games. These were examined in two ways. First, sex differences were expected in the frequency of types of play and recess activities, and in the size of social networks (Belle, 1989; Fiering \& Lewis, 1989; Pellegrini \& Smith, 1998). Blatchford (1996) found that there were differences between boys and girls in games at 11 years. Girls were more likely than boys to play seeking games, pretending games, and skipping games. Daring games, guessing games, pretending games, games using playground markings, ring games, rhymes and clapping games and games using marbles or other materials were rarely or never mentioned, and only by girls. Boys seemed involved but less varied in their play than girls. Football and other ball games dominated their playground activities. However, these results concerned children at the end of the primary school stage, and were based on child report rather than direct observation. In the present study interest was in sex differences in younger children and on the basis of systematic observations on playgrounds.

General predictions were made on the basis of previous research and theory. Crombie and Desjardins 1993 (in Maccoby, 1998) observed free play of $4^{\text {th }}$ and $6^{\text {th }}$ graders and found boys spent the majority of their play time in games while girls spent much less. It was expected that boys, more than girls, would engage in physically vigorous games, like chasing, catching and seeking games, and ball games, and in line with previous research (Pellegrini, 1995) boys would engage in more rough and tumble play. It was also expected that boys would engage in more aggressive activities and, perhaps in consequence, be more likely to be told off on the playground by adults. Girls, however, should be more frequently observed in games requiring verbal facility, such as chanting and jump rope games, given sex differences in oral language production (Maccoby \& Jacklin, 1974). Previous research would suggest that boys tend to play in larger groups, though there is dispute over whether this is the results of

girls and boys playing different games (Benenson, Apostoleris \& Parnass, 1998). Distinguishing between active and game networks, as described above, as well as the types of games, should help 


\section{The Social context of school playground games}

clarify the situation further.

Sex differences were studied in a second way, in terms of the segregation or integration of boys' and girls' play groups. It has been found that boys can play with other boys because they enjoy physically vigorous activities; girls segregate themselves from boys' play groups because they do not enjoy rough play (Pellegrini \& Smith, 1998). But there is dispute about the extent of same-sex play. Blatchford (1998) found in a small scale study evidence for more play over the year involving boys and girls. A freeing-up of social relations between the sexes seemed to result in the onset of more interesting hybrid games. Thorne (1993) has used the term 'borderwork' to describe cross-gender playground chasing games, in which girls often create safety zones, for example, toilets adjoining the playground, to which they can retreat. But evidence to date on the extent of same sex play, and the extent to which same sex activities vary according to the type of playground activities and games, is limited. We were particularly interested in the extent and development of same sex play groups immediately after entry to the junior school stage when, as said above, games are likely to be most salient and important in mediating social relations. In line with Blatchford's (1998) study, it was predicted that same sex game groups would be most frequent but that there would be some mixed sex groups and this would increase over the school year.

\section{The ethnic mix of game groups}

A third interest was in ethnic differences in playground games. One dimension of adjustment to school, especially in ethnically diverse societies, such as the USA and the UK, involves relations between children from different cultural and ethnic backgrounds. Previous research in the UK indicated that ethnic differences were less influential than gender differences in affecting recess activities (Blatchford, 1996). However, this finding was based on interviews with children, which may not reflect actual behaviour, and was based on a study of inner London schools, which had a long standing tradition and experience of multi-ethnic education.

A basic tenet of school desegregation in the USA has been to provide opportunities for diverse 


\section{The Social context of school playground games}

students to interact with each other in integrated schools. This should result in interaction between children from different ethnic groups, with the hope of more integration between groups. The extent to which this ideal corresponds to the reality of school and playground life, however, is not clear. Social psychological theory has usually assumed that mere contact between people from different ethnic groups is not sufficient to bring about ethnic integration (Sabini, 1992). But it is unclear how much contact between ethnic groups occurs in the context of informal and child directed activities, away from adults. Boulton \& Smith (1993), in their observational study of primary school children on playgrounds in the north of England, found same ethnic group preferences. But early observations on playgrounds conducted for the present study in culturally and ethnically diverse English primary schools indicated a surprising degree of ethnic integration in playground games. It was decided to study this more systematically by examining the ethnic integration in playground play groups in England. Based on the assumption that experience with different children would decrease segregation by ethnicity, we also hypothesised that children's groups would become more ethnically diverse with time after entry to school.

One final interest was in the age mix of playground games. Given the role that older children play in the transmission of games outside school (e.g. Opie \& Opie, 1969) the extent of mixed age groups on playgrounds may be important.

\section{Method}

\section{$\underline{\text { Design }}$}

Children entering junior school in England were studied during the year they become 8 years for one year after entry. Longitudinal designs are less common than cross sectional designs, but their value in understanding stability and change in peer relations has been pointed out by Hartup (1989), Furman (1989), Belle (1989) and Rubin, Bukowski \& Parker, (1998). Ladd and colleagues (Ladd \& Price, 1993) used a short-term longitudinal design to good effect in order to study causal effects of social status and styles of playground behaviour. Pilot work indicated the value of a short-term longitudinal 


\section{The Social context of school playground games}

study after entry to school as a way of studying the social contexts within which games and friendships originate, and processes of change and stability in games, friendships and social networks.

The research involved a number of quantitative and qualitative research methods, which were conducted at the start and end of the school year. The main form of data collection involved systematic observations of pupils, but questionnaires completed by pupils, and teacher and research ratings of pupils were also collected. Data were collected twice, first towards the start of the autumn term and again towards the end of the summer term. In addition, in the spring term, observations of games as events were conducted, along with continuous observations of and interviews with pupils selected for case studies, and interviews with a sample of pupils about games and friendships. Only data from the systematic observations are reported in this paper. Results concerning individual differences and social and game networks are reported in Blatchford, Baines \& Pellegrini (2001) and Baines \& Blatchford (2001) respectively, and connections with school adjustment and social competence are reported in Pellegrini, Kato, Blatchford and Baines (in press).

\section{$\underline{\text { Sample }}$}

Four classes of children of 7-8 years in four schools (one class per school) in England were involved in the project. Schools were approached about the project and asked if they would like to take part. All schools approached agreed. Three schools had one class of new children of the same age, while one school was a three form entry school and only one class was involved in the research. The four classes constituted a sample size of 129 pupils (119 pupils were present at the start and end of the year) and this size was considered appropriate in order to provide the basis for reliable quantitative analysis, but also the detail and depth of data required for systematic observations and insightful qualitative approaches (not reported here). There were 61 boys and 68 girls in the sample $(47 \%$ and $53 \%$ respectively of the sample as a whole).

\section{$\underline{\text { School playgrounds }}$}

The 4 school playgrounds varied in size, physical layout and in the availability of materials as well 


\section{The Social context of school playground games}

as on other dimensions. Playground sizes were medium, small, large and very large for Schools 1 to 4 respectively. Schools 1-3 typically had between 150 and 180 pupils on them, while school 4 , with the largest playground, only had to accommodate 120 pupils. The area per pupil for each of the playgrounds was for Schools 1 to 4 respectively: $14^{2} \mathrm{~m}, 18^{2} \mathrm{~m}, 19^{2} \mathrm{~m}$ and $27^{2} \mathrm{~m}$ per child. The playground of school 3 did not have any grassed areas to play on. For the other schools access to grassed areas was restricted to the summer months. Children shared the playground with children of different ages in all schools. Determining whether playmates were of the same age or older was straightforward. In the three one form entry schools if they were unknown to the researchers then they were of a different age. In the three-form entry school, researchers were familiar with the selected class and the children in other same-age classes. In terms of fixed props, all school playgrounds had markings on the surface for games such as hopscotch, basketball and football. Schools 2 and 3 also had apparatus on which to play and schools 1 and 4 had 'quiet areas'. All playgrounds had benches for pupils to sit on. Schools had a range of portable props for pupils to play with. Schools 2 and 3 virtually always had balls, bats, skipping ropes and even pens and paper to play with. These resources were also available in schools 1 and 3 but only at particular times. For school 1 this was only for 15 minutes in the afternoon and school 4 primarily during the summer though from time to time during the autumn term. Schools 1 to 3 had 3 recess periods, typically 15 minutes in the morning and afternoon and about an hour at lunchtime. School 4 did not have a recess period in the afternoon. There were between 2-3 adults present on all school playgrounds, this being teachers for the morning and afternoon recess periods and other adults during the lunch period.

\section{Data collection: Observations of playground behaviour and games}

A main task was the development of an observation methodology able to capture the games and activities occurring on playgrounds. In previous research on long term changes (Blatchford, 1996), children's own accounts were used, and this has certain virtues, but systematic observations are likely to 


\section{The Social context of school playground games}

provide the most reliable and detailed data, that will allow group and time comparisons. A technique involving direct systematic scan sampling observations of pupil behaviour during break-time was developed on the basis of previous research (e.g. Blatchford, Creeser \& Mooney, 1990; Boulton, 1992; Humphreys \& Smith, 1987; Ladd \& Price, 1993; Pellegrini, 1995). Scan observations of each pupil in the class were conducted for the duration of every recess period over two weeks in the autumn and summer terms, constituting 16 weeks of observation in total. All recess periods were observed including lunchtime. These amounted to about 90 minutes per day. Every 20 seconds a child from the class was scanned and their playground behaviour recorded, via a commentary using a tape recorder and hidden microphone, in terms of pre-selected categories. The order of children to be observed, one after the after, was counter-balanced across time and recess period. Observers also spent time in the children's classrooms or took children out of class time to collect other forms of data from the children, and so got to know the children well. This aided identification of study children on the playground (when other classes were also present). There were three observers: one (male) observed throughout the year, one (female) in the first half and one (female) in the second half of the year. The first observer (Baines) was involved in the design of the schedule and had extensive experience of live and video observation; the other two observers were trained on the basis of video recordings and field visits, with constant checks of codings and understandings of category definitions.

\section{$\underline{\text { Categories }}$}

Within each dimension categories were mutually exclusive.

Contextual information. Details of fixed and portable apparatus being used by the target child or colleagues within the activity and also the location of the child/ children were recorded.

Level of social interaction with peers. Children were coded as being in one of 3 states of social interaction.

i. Solitary - the target child is not interacting or in a parallel activity with other pupils irrespective of 


\section{The Social context of school playground games}

proximity, e.g. standing on the edge of a game watching, but not when involved in a game (e.g. in soccer the goalkeeper is often alone but is involved in game).

ii. Parallel - the target child is situated in close proximity to another child and they are both doing the same activity but are not talking or interacting in a socially organised activity.

iii. Social - the target child is engaged in physical and/or social interaction or involved in a socially organised game or activity (includes children doing parallel activities but also talking). So a child that is standing alone against a wall as part of a game (e.g. 'it with bases', or the goalkeeper in soccer) should be coded as 'social'.

Type of activity. Children were coded as engaged in one of the following activities.

i. Conversation - the target child is involved only in conversation and when asked what they are doing they say just talking or something to the same effect.

ii. Vigorous play - the target child is engaged in vigorous activity, (e.g. cartwheels, spinning, running etc.)

iii. Sedentary play - the target child is engaged in non-vigorous activity (e.g. drawing, reading, playing with cars etc.)

iv. Fantasy play - the target child is engaged in imaginative/role play. This supersedes vigorous/ sedentary play (e.g. mums and dads, families, cops and robbers, 'Jerry Springer', 'Poke’mon’ etc.)

v. Chasing/ catching/ seeking - the target child is involved in a game where pupils run after or look for others with the aim of touching (physically or with an object usually a ball, thus this supersedes ball games), catching (no object involved), or just seeing them.

vi. Racing - the individual is involved in a racing competition with others the aim being to win. They may compete together, as pairs etc. or time each other.

vii. Ball games - the target child is involved in a game within which players use a ball, including pig in the middle, throwing and catching, tennis, soccer, basketball etc. and other derived games e.g. kickball. 


\section{The Social context of school playground games}

viii. Jump skipping - the target child is involved in a game where individuals skip with a rope each or where a rope is shared.

ix. Games with materials - the target child is involved in other games with rules that use materials, (e.g. throwing hoops over pegs, board games, Frisbee etc.)

$\mathrm{x}$. Verbal games - the target individual is involved in an activity where children sing or say verbal rhymes (e.g. dipping ('eanie meanie minie mo'), actions and rhymes or singing and dancing etc. (unless this is accompanied by another category, e.g. skipping, when it is superseded).

xi. Other - Where the target individual is involved in activities that are not covered by non-games or games above (e.g. musical statues, please Mr Crocodile, hop-scotch etc.)

xii. Nothing - no activity/game or play

Behaviour. Children's behaviour was coded according to the following categories:

i. Onlooker - Where the target individual watches others engaged in an activity/game/interaction. $\mathrm{He} / \mathrm{she}$ may be out of the game or even involved in the game but just watching the action.

ii. Unoccupied - target child is not doing anything and not watching others.

iii. Disputing - target individual involved in arguing or ganging up on others - may include verbal abuse, and supersedes teasing and taunting but not aggression.

iv. Tease/ taunt - target child is involved in verbal teasing and taunting of others (e.g. derogatory name calling) as part of a game (e.g. 'you can't catch me') or framed in a more dispute-like or aggressive context.

v. Rough \& Tumble play - target is involved in play fighting - what may look like aggressive acts (e.g. hitting, wrestling, kicking etc) but children remain together - no active avoidance and splitting up after.

vi. Aggression - the individual is involved in giving or receiving an aggressive act (verbal or physical).

vii. Positive affection - where the child is continuously touching a peer in some affectionate way 


\section{The Social context of school playground games}

(e.g. arm around shoulders, arms linked etc.).

viii. Distress/ crying - when the target child cries or is upset for some reason.

ix. Disciplined - where the child is either being told off by the teacher or has been put against the wall, must stay with teacher, or is sent to the Head Teacher or kept in to be disciplined etc.

x. Other - This category was used to code other behaviour not covered by the preceding categories.

Networks. If children were engaged in parallel or social interaction, information was recorded on their active and game networks

i. Active social network - the number, identity, sex, ethnicity, and age of other persons that the target child is actively interacting with (e.g. talking or listening to, physically engaged with etc.) were recorded.

ii. Game/ play network - the number, identity, sex, ethnicity, and age of other persons that are involved in the same the social network/ game or activity as the target child were recorded.

Adult presence and involvement. The presence or involvement of adults with the target was noted. 'Present' was defined as within 6 feet of target. Not actively involved (i.e. pupil does not talk to or listen to adult) was defined in terms of being present but may be watching. 'Involved' was defined in terms of child talking to or listening to adult. The number and identity (teacher, supervisor, other) of adults present or involved with the target was also recorded.

On occasions when it was difficult for the researchers to identify what the children were doing, for example whether they were playing a fantasy game or just engaged in conversation, the researchers asked the children whether they were doing anything or not (to avoid demanding a made up response) and if so what the activity was. The researchers discouraged the children from initiating conversations with them on the playground but allowed this in the classroom. This actually facilitated un-obtrusive observations as in the classrooms, but not the playground, children were given plenty of opportunities to ask questions about the research and what the researchers were doing. 


\section{The Social context of school playground games}

$\underline{\text { Analysis }}$

The aim of the scan observations was to provide basic frequencies for each child of selected playground behaviours. These observations resulted in a total of 7906 scans, an average of 26.5 scans per child in the autumn and 37.5 scans per child in the summer term. Data were entered directly from the tape recordings into a spreadsheet. This produced two data sets, a scan level data set where the case was the scan and a child level data set where the observations for each child were aggregated so that the child was the case. For the child level data set, the scan data for each child was totalled and divided by the number of scans of the target child to give a percentage of scans that a child was observed engaged in a particular activity, behaviour etc. The game and active network sizes and sex mix excluded the target child, and the age mix and ethnic mix were judged in relation to the target child. The child level data set gave a proportional measure of the amount of scans spent engaged in each activity/ behaviour. ANOVAs (see below) were conducted on the child level data set. Training and calibration of understanding of coding categories was continuous over the observation periods. Inter-rater reliabilities were collected (through about 100 synchronised observations of children) and calculated at the end of observations in the autumn and summer terms using Kappa for categorical variables and intra-class correlations for interval data (See Howell, 1997). Kappa reliabilities exceeded acceptable levels and ranged between 0.72 and 0.95 and intra-class correlations between 0.88 and 0.98 .

\section{Results}

Of the 7906 scans, $46 \%$ were scans of boys playing at recess and $54 \%$ of girls that closely matched the numbers of boys and girls in the sample. In terms of the time points for observations, $42 \%$ of the scans were conducted at time 1 and $58 \%$ at time 2 .

Table 1 about here. 


\section{The Social context of school playground games}

\section{Level of social interaction with peers}

Table 1 shows that there were many more social than either solitary or parallel activities. Two way ANOVAs show that there is a main effect for sex for each category: boys engage in more social, and girls in more parallel and solitary behaviour. Boys are therefore more likely to be involved in games and other activities on the playground involving other children. There were differences between time 1 and time 2 for only one of the three categories: there was an increase in parallel activities by the summer term and this only approached significance.

\section{Game and play categories}

Table 1 shows that the most frequent activities were conversation, vigorous play, sedentary play, fantasy play, chasing, catching and seeking games, ball games. Less common were racing, jump skipping, games with materials, and verbal games.

The activities can be summed to produce three main categories: first, conversation, second, play (vigorous, sedentary and fantasy play) and, third, game categories (chasing, catching and seeking games, racing, ball games, jump skipping, games with materials, verbal games). Play and games each accounted for about a third of activities and conversation a fifth of activities. The remaining $11 \%$ represented no activity, i.e. when children were not engaged in play, games or conversation, such as when children are solitary or parallel onlooking/ unoccupied etc. There were sex and time differences in the total play and game categories, as can be seen in Table 1. There were no sex differences in the total amount of play, but there were time differences and an interaction between time and sex. As can be seen in Table 1, boys tend to play less over the year, while for girls play remains fairly constant. In contrast, boys engaged in significantly more games over the course of the year, while girls decreased their involvement in games overall. For games there was a significant sex and sex by time interaction, but no difference over the year.

There were a number of sex differences in individual categories. As expected, boys were significantly more likely to be involved in ball games, and girls in more conversation, sedentary play, 


\section{The Social context of school playground games}

jump skipping, and verbal games. Interestingly, boys were more likely to be involved in fantasy play, and there were no differences in chasing, catching and seeking games and racing games.

Table 1 also shows differences over time. By time 2 there was noticeably more ball games, and conversation, but less sedentary play, and fewer games with materials and chasing, catching and seeking games.

These changes over time may be connected to seasonal changes. Overall, $87 \%$ of the scans at time 1 were conducted on the playground and $13.1 \%$ were conducted indoors when, because of poor weather, children were unable to play outside. At time 2, during the summer term, when the weather was better, $93.3 \%$ of scans were of children playing on the playground, and only $7 \%$ of scans were taken indoors. When children played indoors this was usually a sedentary activity (65\%) such as Lego or drawing etc. or involved games with materials (16\%) such as board games and other games with rules etc.

With regard to interactions between sex and time, Table 1 shows that the overall decline over time in sedentary play was most marked for boys. For racing, there was some sign of an increase for girls by time 2 but for boys if anything this decreased. Though boys play more ball games overall, there are signs that by the end of the year the increase is greater for girls. That is, for boys ball games doubled but for girls, involvement in ball games tripled. The decline in games with materials was most marked for girls and, according to observers' field notes, this was due to the loss of interest in the game of hopscotch that had been played by a small group of girls in school 4 during the autumn term.

Table 2 about here

\section{$\underline{\text { Behaviours }}$}

Table 2 shows the overall prevalence of the behaviour categories. Overall, these categories were not as frequent as the game categories, and frequencies of some categories - disputing, teasing and taunting, aggressive, distress/crying and being disciplined - were all low. As expected, boys were more 


\section{The Social context of school playground games}

likely to be observed in rough and tumble activities, more aggression and more 'being disciplined' (though these behaviours were all infrequent). Girls engaged in more 'positive affection'. Boys were more often observed onlooking. Table 2 also shows changes over time in these behaviours. By time 2 there was more onlooking, and less positive affection, and distress/crying. None of the interactions between sex and time were significant.

Cross tabulation of game categories and behaviour types (using the scan rather than the child data base), showed that Rough and Tumble was most likely to occur in vigorous play (45\%) and fantasy play (34\%). Aggression was most commonly found in vigorous play (56\%), followed by in conversation (19\%), ball games $(14 \%)$ and fantasy play $(7 \%)$. Disputes between peers were most common in conversation $(56 \%)$ and ball games $(12 \%)$.

\section{$\underline{\text { Network size }}$}

The average active network size was 0.8 (see Table 3 ). There were no differences between boys and girls or differences in size over the year. As expected, the average game network size was larger (3.7). There were sex and time differences in game network size. Boys' game networks were much larger than girls' at both time points and, for both girls and boys, game networks had become larger by time 2 . There were no interactions between sex and time.

\section{$\underline{\text { Sex mix of playground groups }}$}

The sex mix of groups was categorised in terms of whether they were mostly female $(60 \%$ or more of participants were female), mostly male (60\% of participants were male), and mixed sex (no more than $60 \%$ and no less than $40 \%$ of children in groups were of one sex). For both active and game networks, there was a clear tendency for children to be in same sex groups on the playground (see Table 3). In over $80 \%$ of scans boys were in mostly male groups and girls in mostly female groups. Active networks with an equal sex mix, were rare; there were about twice as many game networks with an equal sex mix. 


\section{The Social context of school playground games}

Table 3 about here

The amount of observations in which boys and girls interacted with each other or were in the same game was calculated. This was done by adding the percentage of mixed sex and mostly female groups, and showed that in about $12 \%$ of active networks boys were interacting with girls. For girls the equivalent figure was $14 \%$. In the case of game networks, boys interacted with girls in $13 \%$ of observations, and for girls the equivalent figure was $17 \%$.

Of the activities involving an equal balance of boys and girls (i.e., when there were exactly the same number of boys and girls in each group), the most popular were: conversation (21\%), fantasy play (14\%), chasing, catching and seeking games (13\%) and ball games (16\%).

An analysis using a more 'liberal' definition of mixed sex activity was also conducted. Here mixed sex activity was defined in terms of times boys and girls were in the same group, even when there was just one girl or boy. This indicated that of the total activities when in mixed sex game networks, conversation (17\%), fantasy play (11\%), chasing, catching and seeking games (14\%), and Ball games (25\%) were the most popular joint sex activities. No type of game was more likely to be a mixed sex than single sex activity, though $41 \%$ of chasing, catching and seeking games, $41 \%$ of racing games and $39 \%$ of ball games involved children from both sexes (these percentages mean that e.g., $59 \%$ of racing, and $61 \%$ of ball games, were not joint sex). It should be re-emphasised that very few games had an equal sex mix; rather the vast majority of mixed sex games had a minority of one sex.

There were no changes over time for both active and game networks in the percentage of mostly male, mostly female and mixed sex groups.

\section{$\underline{\text { Age mix of playground groups }}$}

In just over half of the scans, children's active networks involved same age children (i.e., children in the same year group), and far fewer (9\%) were mixed age (percentages fall short of $100 \%$ because data 


\section{The Social context of school playground games}

includes cases where children were not coded as in a network, see Table 3). There was a sex difference in the extent to which active networks were mixed age with girls being more likely to be interacting with children of different ages. There was a tendency for same age active networks to decline slightly over the year.

With regard to the game (as opposed to active) networks, there were more mixed aged networks (24\%) (see Table 3). Boys were more likely than girls to be in same aged game networks, though the sex difference in mixed age game groups was not so clear.

\section{Ethnic mix of playground groups}

Lastly, we turn to the percentages of same and mixed ethnic group active and game networks (see Table 3). These have, of course, to be seen in relation to the number of children from different ethnic groups on the playground and this differed between the four schools. In schools $1-3$, between $41 \%$ and $49 \%$ of children were from between 4 and 6 different ethnic minorities. In school 4 only one child (a girl) had a different ethnic background. In relation to sex, fairly equal proportions of boys and girls from schools 2 and 3 came from different ethnic groups. In school 1 the boys were more evenly spread across the different ethnic groups than the girls, where $79 \%$ of the girls had an UK white background. Overall, children were in ethnically mixed active networks in $25 \%$ of scans, and in same ethnic group networks in $37 \%$ of scans. The equivalent figures for game networks showed that ethnically mixed game networks now outnumbered same ethnic groups ( $49 \%$ and $40 \%$ respectively).

There were sex and time differences in the percentage of same and mixed ethnic group active and game networks. Females were much more likely to be in same ethnic active and game groups, and males to be in mixed ethnic active and game groups. There was also a tendency for same ethnic group active and game networks to decline over the year, while mixed ethnic game groups increased. These broad patterns remained the same when the data for school 4 were excluded from the analysis. 


\section{Discussion}

\section{Frequency of playground games and behaviours and changes over the school year}

In terms of the three main Parten categories, it was found that social activities were far more prevalent than either solitary or parallel activities, confirming that school playgrounds are predominantly sites for social interactions between peers. Against expectation, though, social activities did not increase over the year; indeed, parallel activities had increased by the summer term, though the result was only just statistically significant and there were still far fewer parallel behaviours than social. On closer examination of the observation scan data, and observers' field notes, parallel activity over the year seemed to have changed subtly from engaging in individual play with others nearby, to standing near playmates and watching others involved in play or game activities, for example, watching football, or watching a conversation between other people. In this sense parallel activity had become more connected to growing social activities on the playground by the end of the year.

These children spent recess in three main types of activities: first, conversation, second, play (vigorous, sedentary and fantasy play) and, third, game categories (chasing, catching, seeking; racing, ball games, jump skipping, games with materials, verbal games). Play and games each accounted for about a third of activities and conversation a fifth of activities. The remaining $11 \%$ represented no activity, i.e. when children were not engaged in play, games or conversation, such as when children are solitary or parallel onlooking/ unoccupied etc.

In terms of the types of games preferred by these children, vigorous play, sedentary play, fantasy play, chasing, catching and seeking games, and ball games were the most commonly observed, while racing, jump skipping, games with materials, and verbal games were the least common. It is difficult to exactly compare these results with Blatchford's (1996) results for 11 year olds, because of the different methodology used. In a similar way, though, activities at 11 years were also dominated by active games, and ball games. Racing games and skipping games were also less often noted.

There were differences over time in the frequency of games. In line with expectation there were 


\section{The Social context of school playground games}

noticeably more ball games. This was also found in a parallel project in Minnesota, USA (Pellegrini et al., in press). The decline in sedentary play was probably because this tended to be common during indoor recess and this was more likely in the Autumn term when the weather was more likely to bring this about. Of interest was the significant decline in chasing, catching and seeking games, though mean frequencies show this was not marked overall. If these can be taken as the most representative of what can be seen as 'traditional' games, in that they will include perennial chasing games like 'had', catching games like 'stuck in the mud' and seeking games like 'forty forty', then these results support the view that traditional games decline over the course of the first year at school. In the USA study chasing games also decreased over the year (Pellegrini et al., in press). This result could be due to a variety of factors including the increased availability of materials in 3 of the 4 schools that encouraged other games, particularly ball games. In two schools balls were provided during the summer term when previously they had either not been available or only infrequently; in a third school a new batch of tennis balls were provided over and above the football and basketballs that were usually available.

As well as the influence on games of materials provided by schools, there are also a number of social processes that might be connected to changes in games played. As suggested by Blatchford (1998), these could include the influence of older children in school on what games were played. Familiarity among peers may also have contributed to the increase of ball games across time. Another possible factor relates to intrinsic qualities of the games themselves, with some games being seen as 'boring', and some exciting. More careful exploration of the nature and balance of social and non social factors affecting changes in games over time is still needed. In future research it is also hoped to provide a systematic account of changes with age by examining at the end of junior school (i.e. 10/11 years) the playground games of the sample of children in the present study. These results also highlight the likely influences of school differences in playground games and activities and this is taken up in a separate paper (Blatchford and Baines, in preparation).

The most obviously negative behaviours such as aggression, teasing/taunting, disputing, were all 


\section{The Social context of school playground games}

infrequent, as were incidents when children were told off or disciplined by an adult. In general this indicates that negative experiences on the playground, at least as observed in this study, are very rare, and that involvement in social and game activities were far more common. These findings indicate that a view of break time activities as predominantly conflictual and negative would be wrong. There is a connected view that some games, especially football, can lead to arguments and confrontations and cause problems once children return to the classroom (Blatchford, 1989). However, cross tabulation of game and behaviour types indicated that the more obviously confrontational behaviours were not more likely to be in the context of ball games like football. Aggression was most commonly connected with vigorous play and conversation, and disputes between peers were most common in conversation.

\section{$\underline{\text { Sex differences in games and other behaviours }}$}

Boys engaged in more social, and girls in more parallel and solitary, behaviour, showing that playgrounds are social settings particularly for boys. There were interesting sex and time differences in the total play and game categories. Boys spent more time than girls in games, and their involvement in games becomes more marked after entry to school at the same time as their involvement in play declines. Girls interest in play stayed fairly constant over the year, but their interest in games, already less than boys, declined over the year. Predictions that game activities would increase over time at the expense of play therefore applied to boys but not girls.

There were a number of sex differences in the frequency of individual categories that were in line with predictions. As expected boys were significantly more likely to be involved in ball games, and girls in more conversation, sedentary play, jump skipping, and verbal games. This tends to reinforce the view that when boys are put into a context that affords opportunity for physically vigorous activity, such as a playground, sex differences are observed. Girls, on the other hand, are verbally more facile and sedentary than boys and games utilising these skills, such as skipping, chanting and clapping games, showed corresponding female preference.

Interestingly, boys were more likely than girls to be involved in fantasy play. However, observers' 


\section{The Social context of school playground games}

field notes indicated differences between boys and girls in the kinds of fantasy activities; for boys fantasy play was often a site for rough and tumble and physical activity, while for girls fantasy play tended to be more sedentary. Boys' fantasy play was often based on action computer games, films and TV cartoons, while girls' fantasy play was more likely to be based around what might be seen as more traditional themes of babies, families and horses. At the end of the school year, much fantasy play among boys and girls had become connected to the then very popular 'Poke'mon' TV Series and cards. But even here their activities differed: whereas boys tended to take on the roles of particular characters, the girls adapted the themes so that they involved babies, horses or family components to the game. One possible reason for the sex difference in fantasy play was that it offered those boys that did not engage in athletic games such as ball and racing games an outlet for physical activities. Indeed, there were certain groups of boys who were particularly keen on fantasy play (particularly in schools 1, 3 and 4) and would spend almost the whole of each recess involved in this type of play. By comparison there were no girl groups that were so exclusively devoted to fantasy play.

Analysis of interactions between sex and time showed some interesting trends that amplify the analysis of sex differences in play. The overall decline over time in sedentary play was most marked for boys and, despite a decline in the amount of indoor play, girls engaged in almost similar amounts of sedentary play during the summer term. In one school in particular there was a noticeable increase in the amount of outdoor sedentary play among girls - e.g. in terms of drawing and reading. In the case of racing games, there was some sign of an increase for girls but for boys if anything a decrease. Though as expected boys play more ball games overall, there are signs that over the year they increase more for girls. These results are interesting in that they indicate that over the year it is girls who become more actively and physically involved in racing and ball games.

However, the observers' field notes indicate some important differences underlying the general trend. In 3 of the 4 schools, girls were at some point in the summer term involved in ball games such as football and basketball - though this was always a minority of girls, and usually the more athletic ones. 


\section{The Social context of school playground games}

In one school girls were more likely to play 'stone-ball', 'champ' or tennis than boys. These games are less vigorous physically and players were less likely to bump into each other. So although there were certainly some girls interested in football and basketball, and this might go some way to explaining the overall increase over the year, other girls enjoy playing other kinds of ball games that are less vigorous and parallel to more physical games like football. Given the opportunity, therefore, girls can like some ball games, but might well avoid others such as football.

The data suggest that for boys the activity or game was the primary focus which brought them together, while girls seemed more likely to come together to socialise, independent of a game that might support their interaction. As we have seen, boys were more likely to engage in games than girls. While girls were engaged in play or games for an average of $58 \%$ of scans (derived from an addition of the play and game categories) this figure was $85 \%$ for boys. In terms of game networks, when boys were allowed to play football it would involve almost all of the boys from the class - indicating that it was a mutual interest in this activity that brought these children together. When they were not allowed to play football they would split into smaller groups to play a variety of games including chasing, fantasy, racing etc. games. Many of the games that boys played lasted for the full duration of a break time or would end and be followed by another game/ activity. Girls on the other hand would not play one single game for the duration of a break time, would rarely ever come together as a whole group to play a game, and often games were fairly short and interspersed with conversation. Further research is needed to examine sex differences. It would be interesting for future researchers to examine girls' engagement in games in all female schools. It may be that girls are more engaged in more varied games in situations where they do not have to compete with boys for space and physically within the game.

There were some expected findings concerning sex differences in behaviour types. Boys were more likely to be observed in rough and tumble activities, more aggression and more 'being disciplined' (though these behaviours were all infrequent, as we have seen). Girls were engaged in more 'positive 


\section{The Social context of school playground games}

affection'. However, there were some unexpected results. Onlooking increased over time and boys were more likely to be onlooking than girls. Both of these effects are linked to the higher level of ball games at time 2 and among boys in particular. Ball games involve a lot of onlooking activity particularly when the ball is not near the target participant (e.g. football) or when children queue up to play the game (e.g. champ, stone-ball). This suggests that while ball games increased in their prevalence, actual direct involvement may not have increased to the same extent.

\section{$\underline{\text { Sex mix of game groups }}$}

There was a clear tendency for children to interact on the playground with children of the same sex and for them to be involved in same sex games. In over $80 \%$ of scans boys were in mostly male groups and girls in mostly female groups. Mixed sex groups, that is groups which involved no less than $40 \%$ of one sex, were not common, though boys did interact overall with females in either mixed or predominately female groups in $13 \%$ of scans and girls with boys in $17 \%$ of scans. However, there were very few games which had an equal sex mix; rather the vast majority of mixed sex games had a minority of one sex. These results show that sex segregation of playground game groups is marked, as it is in the USA in similar aged children (Pellegrini et al., in press). Contrary to Blatchford's (1998) suggestion, there was no sign at all that same sex groups increased over time; the degree of sex segregation remained constant over the year. This discussion indicates that cleavage between boys' and girls' play and activity is common but not inevitable. There did not appear to be particular games which supported more mixed sex play; rather there were a number of games that brought boys and girls together, the most likely being ball games, conversation, chasing catching and seeking games and fantasy play. But evidence to date on the extent of same sex play is limited and more systematic study of joint involvement in playground activities and games over time after entry to school should help illuminate the contexts and processes leading to collaboration and separation between the sexes.

\section{$\underline{\text { Active and game network sizes }}$}

The results concerning network size confirmed the value in separating active from game network 


\section{The Social context of school playground games}

sizes. There were no sex differences or differences over time in the active network size, that is, in the number of other children with whom the target child was actively engaged. But there were sex and time differences in the game network size, that is, in the larger number of children in the same game or activity. These results show that boys tend to play games involving larger groups (as suggested by previous research), and for game groups to get larger over time. This was mainly due to the increase over time in ball games, which typically involved more children.

The distinction made in this study between active and game networks might also help clarify contrary predictions concerning changes in time. In line with predictions based on Blatchford's (1998) suggestion, noted above, it is the 'active' network size which appears to be stable (i.e., not increase), while it is the game network which increases over time, perhaps with familiarity and more interest in games with rules.

\section{$\underline{\text { Age mix of game groups }}$}

In just over half of the scans, children's active networks involved same age children, and far fewer were mixed age. When the game network was considered there were more mixed age groups. This indicates that though children tend to interact with children of the same age they are involved in games with more children from other years. There was a tendency for girls, more than boys, to interact with children from other years, and also to be in games with more children of other ages. There was also a tendency for same age networks to decline over the year. For the most part the children from different year groups will be older, and so these results show a tendency overall for children to play and interact more with older children after entry to school and for this to be most marked for girls. The Opies (Opie \& Opie, 1969) have offered a view that games outside school are largely acquired through interactions with older children and siblings. Given that the settings within which children play out of school have quite likely decreased since the 50s, as parents become concerned with dangers from traffic and strangers, it may be that games are passed on through interactions with older children on school playgrounds. However, as noted above, the processes involved are in need of more attention from 


\section{The Social context of school playground games}

researchers.

\section{Ethnic mix of game groups}

Lastly, we turn to the ethnic composition of game groups on the playground. Overall, children were slightly more likely to actively interact in same ethnic than mixed ethnic groups; but in the case of game networks this was reversed. In other words, children were more likely to be in games with children from other ethnic groups than in single ethnic game groups. Though difficult to test exactly, these results indicate a degree of ethnic mixing in games that seems roughly comparable with the proportions of children from different ethnic groups, and therefore there is little obvious sign of ethnic group segregation. Moreover the prediction that play groups would become more integrated with time was supported in these English schools.

Girls were more likely than boys to be in game networks consisting of children with the same ethnic background and less likely than boys to be in mixed ethnicity game groups. This may indicate that girls are more likely to segregate themselves according to ethnicity. However, boy game groups were often larger than girl game groups, and there was therefore a greater likelihood of them being of mixed ethnicity. Further research should look at this in more detail as well as relations between friendships and play partners. It may be the case that close play partners and friends are usually from the same ethnic group but that children from different ethnic groups can come together to play games.

We need to be cautious about extrapolating from these results to schools more widely, particularly as they contrast with the findings from Boulton \& Smith (1993) who found more ethnic segregation in games in schools in the north of England. Much will depend on the exact ethnic groups involved, and the schools in the studies. But in these English junior schools there appears to be more play and interaction involving children from different ethnic groups, especially in the case of boys. This confirms more anecdotal observations of games where ethnicity seemed irrelevant to the composition of groups.

These findings indicate one way in which playground activities may have a positive role in the 


\section{The Social context of school playground games}

social relations between different ethnic groups. As we have said, playground activities can be inherently motivating and enjoyable for a lot of children, and children on the playground are drawn to play with each other and engage in games like football and other ball games. Interestingly, football (and other ball games more generally), which often causes problems for schools, and about which school policies regarding the use of the playground may be deemed necessary, may have a positive role in drawing children (usually boys) from different backgrounds together. As has been argued before (Blatchford et al., 1990), it is difficult to over stress the role that football can play in the playground activities and indeed lives of many English boys. Contact theory is usually assumed to be inadequate as a way of bringing about ethnic integration, and social psychologists long ago showed that some form of superordinate goal is needed to bring about integration and co-operation (Sabini, 1992). It is possible that informal child-organised activities, like football, may do more than externally and adult imposed schemes to facilitate real integration by creating 'authentic' joint activities involving different ethnic groups. However, this suggestion requires further examination. Further research should also examine the ethnic mix of game and playground groups relative to age; once the game structures that may support interactions between pupils from different ethnic groups die out social networks may revert to ethnic segregation.

Ball games like football may have another positive role. To successfully interact with peers and to engage in games requires a fair level of social and cognitive sophistication, in that children must know the rules of the games and subordinate their personal views and desires to a priori rules. Even informal observations of football games on playgrounds can indicate a surprisingly complex and rule governed game, often with localised and contextually driven variations (e.g., adapting to the spaces and playground available). These sorts of games can be cognitively and socially complex, with numerous roles and rules in each game which children must comprehend, follow, and negotiate with their peers. The necessary social and cognitive skills to play these games are developing during this period (Garvey, 1978), and disagreements between players must be negotiated for games to continue. General 


\section{The Social context of school playground games}

social cognitive development across the school year may have been partially responsible for these time related increases, but it may also be that participation in the socially and cognitively rich game of football in turn has benefits in these areas. We believe that careful and detailed study of children's everyday participation in football is long overdue.

Lastly we consider recess more broadly. Unfortunately, there are signs that time allocated for recess and lunchtime is being reduced, and management policies are resulting in the erosion of traditional pupil freedoms (Blatchford \& Sumpner, 1998; Pellegrini, 1995a). A concern with difficulties individual children experience during recess is clearly important, but the present study indicates that this worry might be turned on its head in favour of a view that children learn much about social relationships and skills during the course of everyday encounters with peers during games. Cutbacks in recess are thus likely in the long term to exacerbate the problems they are implemented to stop.

The results also indicate the value of looking closely at game and playground activities as a guide and reflection of adjustment to school. To an interesting degree this information is not normally available to teachers who in the UK at least spend a limited time in playground supervision. Such information can be of use in the case of children having difficulties at school; but it may be of use in a more general way as a guide to children's adjustment to school.

\section{Notes}

In this paper the terms breaktime, playtime, and recess are synonymous and refer to all breaks during the school day, including lunch breaks.

\section{Acknowledgements}

The authors would like to acknowledge support from the Spencer Foundation (Major Grant Number 199800204). The authors are grateful to all the schools, teachers and most importantly the pupils who participated in this research. 


\section{References}

Baines, E. \& Blatchford, P. (2001) The nature of young children's friendship relations: what can we learn from playground game networks? Part of symposium on: Playground games and social relations: their social context in elementary/ primary school presented at Biennial conference of the Society for Research in Child Development April 2001

Belle, D. (1989) Studying children's social networks and social supports. In D. Belle (Ed.), Children's Social Networks and Social Supports. New York: Wiley.

Benenson, J., Apostoleris, N. \& Parnass, J. (1998) The organisation of children's same sex peer relationships In W.M. Bukowski \& A.H. Cillessen (Eds.) Sociometry then and now: building on six decades of measuring children's experiences with the peer group. San Francisco: Jossey-Bass Publishers.

Blatchford, P. (1989) Playtime in the Primary School: Problems and Improvements. Windsor: NFER-Nelson. Now, London: Routledge.

Blatchford, P. (1996) 'We did more then': Changes in pupils' perceptions of breaktime (recess) from 7 to 16 years. Journal of Research in Childhood Education, 11, (1), 14-24.

Blatchford, P. (1998) Social life in schools: pupils experiences of breaktime and recess from 7 to 16 years. London: Falmer Press.

Blatchford, P. \& Baines, E. (in preparation) Differences between schools in 


\section{The Social context of school playground games}

playground games and activities.

Blatchford, P., Baines, E. \& Pellegrini, A. (2001) A typology of playground involvement: individual differences and their correlates. Part of symposium on: Playground games and social relations: their social context in elementary/ primary school presented at Biennial conference of the Society for Research in Child Development April 2001

Blatchford, P., Creeser, R., \& Mooney, A. (1990) Playground games and playtime: The children's view. Educational Research, 32, (3), 163-174. Reprinted in M. Woodhead, P. Light and R. Carr, (Eds.) (1991) Growing Up in a Changing Society. London: Routledge/Open University.

Blatchford, P., \& Sumpner, C. (1998) What do we know about breaktime?: Results from a national survey of breaktime and lunchtime in primary and secondary schools. British Educational

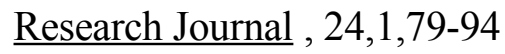

Boulton, M. (1992) Participation in playground activities at middle school. Educational Research, 34, (3), 167-182.

Boulton, M. \& Smith, P.K. (1993) Ethnic, gender partner, and activity preferences in mixed-race children's social competence develops in the context of interacting with their peers schools in the U.K.: Playground observations. In C. Hart (Ed.), Children on playgrounds, (pp. 210-238). Albany: SUNY press.

Crombie, G., \& Desjardins, M.J. (1993) Predictors of gener: the relative importance of 


\section{The Social context of school playground games}

children's play, games and personality characteristics? Paper presented at the biennial meeting of the Society for Research in Child Development, New Orleans, March

Fein, G. (1981) Pretend play in childhood: An integrative review. Child Development, $52,1095-1118$.

Fiering, \& Lewis, M. (1989) The social networks of girls and boys from early through middle childhood. In D. Belle. (Ed.), Children's Social Networks and Social Supports. New York: Wiley.

Furman, W. (1989) The development of children's networks. In D. Belle. (Ed.), Children's Social Networks and Social Supports. New York: Wiley.

Garvey, C. (1978) Play, Fontana

Hartup, W.W. (1989) Behavioural manifestations of children's friendships. In T.J. Berndt and G.W. Ladd (Eds.), Peer Relationships in Child Development. New York: Wiley.

Hillman, M. (1993) One false move... In M. Hillman (Ed.,) Children, Transport and the Quality of Life. London: Policy Studies Institute.

Howell, D.C. (1997) Statistical methods for psychology. Fourth Edition. London: Duxbury Press.

Humphreys, A.P., \& Smith, P.K. (1987) Rough and tumble, friendship, and dominance 


\section{The Social context of school playground games}

in schoolchildren: Evidence for continuity and change with age. Child Development, 58 , 201-212

Ladd, G.W. \& Price, J.M. (1993) Playstyles of peer-accepted and peer-rejected children on the playground. In C.H.Hart (Ed.). Children on Playgrounds: Research Perspectives and Applications. Albany, N.Y: State University of New York Press.

Maccoby, E. \& Jacklin, C. (1974) The psychology of sex differences. Stanford, CA: Stanford University Press.

Maccoby, E. (1998) The two sexes: growing up apart, coming together. London: Harvard University Press.

Opie, I., \& Opie, P. (1969) Children's Games in Street and Playground. London: Oxford University Press.

Parker, J.G., \& Gottman, J.M. (1989) Social and emotional development in a relational context: friendship interaction from early childhood to adolescence. In T.J. Berndt and G.W. Ladd (Eds.), Peer Relationships in Child Development. New York: Wiley.

Parten, M.B. (1932) Social participation among school children. Journal of Abnormal and Social Psychology. 27 243-269.

Parten, M.B.(1933a) 'Leadership among preschool children', Journal of Abnormal and Social Psychology, vol. 27, 43C-440. 
Parten, M.B. (1933b) 'Social play among pre-school children', Journal of Abnormal and Social Psychology, vol. 28, 136-147.

Pellegrini, A.D. (1995) School Recess and Playground Behaviour: Educational and Developmental Roles. Albany, New York: State University of New York Press.

Pellegrini, A.D. \& Blatchford, P. (2002) Time for a break: the developmental and educational significance of breaktime in school. The Psychologist, 15,2, 60-62

Pellegrini, A., Kato, K., Blatchford, P., and Baines, E. (in press) A short-term longitudinal study of children's playground games across the first year of school: implications for social competence and adjustment to school. American Educational Research Journal

Pellegrini, A. D, \& Smith. P K. (1998) Physical activity play: The nature and function of a neglected aspect of play. Child Development, $68,577-598$.

Piaget, J. (1965) The moral development of the child. New York: The Free Press.

Rubin, K.H., Bukowski, W. \& Parker, J. (1998) Peer interactions, relationships, and groups. In W. Damon (Ed.), and N. Eisenberg (Vol. Ed), Handbook of child psychology : Vol. III: Social emotional and personality development, (pp.619-700). New York: John Wiley.

Rubin, K. H., Fein, G., \& Vandenberg, B. (1983) Play. In E.M. Hetherington (Ed.), 
The Social context of school playground games

Handbook of child psychology: Vol. IV. Socialization, personality and social development, (pp.693-774). New York: Wiley.

Sabini, J. (1992) Social Psychology, Norton: New York

Sluckin, A. (1981) Growing Up in the Playground: The Social Development of

Children. London: Routledge \& Kegan Paul.

Sutton-Smith, B. (1982) A performance theory of peer relations. In K.M. Borman

(Ed.), The Social Life of Children in a Changing Society. Hillsdale, New Jersey: Lawrence Erlbaum Associates.

Thorne, B. (1993) Gender Play: Girls and Boys in School. Buckingham: Open University Press. 
The Social context of school playground games

Table 1: Mean proportion of scans and ANOVA F values for level of social interaction and type of activity the children were involved in.

\begin{tabular}{|c|c|c|c|c|c|c|c|c|c|c|c|c|}
\hline & \multicolumn{3}{|c|}{ Time 1} & \multicolumn{3}{|c|}{ Time 2} & \multicolumn{3}{|c|}{ Overall } & \multicolumn{3}{|c|}{ ANOVA } \\
\hline & $\begin{array}{c}\text { Male } \\
\text { M }\end{array}$ & $\begin{array}{c}\text { Female } \\
\text { M } \\
\end{array}$ & $\begin{array}{c}\text { Total } \\
\text { M }\end{array}$ & $\begin{array}{c}\text { Male } \\
\text { M }\end{array}$ & $\begin{array}{c}\text { Female } \\
M \\
\end{array}$ & $\begin{array}{c}\text { Total } \\
\text { M } \\
\end{array}$ & $\begin{array}{c}\text { Male } \\
\text { M }\end{array}$ & $\begin{array}{c}\text { Female } \\
\text { M }\end{array}$ & $\begin{array}{c}\text { Total } \\
\text { M }\end{array}$ & $\begin{array}{c}\text { Sex effect } \\
F=(1,117)\end{array}$ & $\begin{array}{c}\text { Time effect } \\
F=(1,117)\end{array}$ & $\begin{array}{l}\text { Sex } \times \text { time } \\
F=(1,117)\end{array}$ \\
\hline Solitary & 9.8 & 12.8 & 11.3 & 8.2 & 10.5 & 9.4 & 8.6 & 11.6 & 10.1 & $3.9^{*}$ & as & ns \\
\hline Parallel & 6.4 & 11.9 & 9.3 & 8.6 & 12.8 & 10.9 & 7.2 & 12.2 & 9.7 & $31.4 * * *$ & as & ns \\
\hline Social & 83.8 & 75.4 & 79.3 & 83.3 & 76.7 & 79.7 & 84.1 & 76.1 & 80.1 & $18.5^{* * *}$ & ns & ns \\
\hline Conversation & 15.2 & 25.8 & 20.8 & 16.5 & 30.9 & 24.4 & 15.4 & 28.4 & 21.9 & $49.6^{* * *}$ & $6.0^{*}$ & ns \\
\hline Vigorous Play & 12.3 & 10.2 & 11.2 & 10.3 & 11.2 & 10.8 & 11.1 & 10.8 & 11.0 & $\mathrm{~ns}$ & ns & ns \\
\hline Sedentary Play & 15.9 & 16.5 & 16.2 & 4.7 & 13.9 & 9.8 & 10.2 & 15.2 & 12.8 & $12.1 * *$ & $31.9 * * *$ & $11.1^{* *}$ \\
\hline Fantasy Play & 13.6 & 5.8 & 9.5 & 16.1 & 6.4 & 10.7 & 14.9 & 6.1 & 10.5 & $17.8 * * *$ & ns & ns \\
\hline Total Play & 41.9 & 32.6 & 36.9 & 31.1 & 31.5 & 31.3 & 36.2 & 32.1 & 34.3 & $\mathrm{~ns}$ & $11.7 * *$ & $7.3^{* *}$ \\
\hline Chasing, Catching, Seeking & 10.0 & 9.2 & 9.6 & 6.9 & 6.4 & 6.6 & 8.7 & 7.9 & 8.3 & $\mathrm{~ns}$ & $10.9 * *$ & ns \\
\hline Racing & 3.1 & 1.7 & 2.4 & 2.0 & 3.0 & 2.5 & 2.4 & 2.3 & 2.4 & ns & ns & $4.9 *$ \\
\hline Ball Games & 14.9 & 1.7 & 7.9 & 28.1 & 6.1 & 16.0 & 22.3 & 3.6 & 13.0 & $43.4 * * *$ & $67.4 * * *$ & $17.1 * * *$ \\
\hline Jump Skipping & .4 & 4.5 & 2.6 & 1.8 & 3.2 & 2.6 & 1.1 & 3.8 & 2.4 & $20.7 * * *$ & ns & as \\
\hline Games with Materials & 3.4 & 7.6 & 5.6 & 1.9 & 1.3 & 1.6 & 2.8 & 4.5 & 3.7 & as & $19.3 * * *$ & $5.8^{*}$ \\
\hline Verbal Games & .6 & 3.1 & 1.9 & .3 & 3.3 & 2.0 & 0.5 & 3.2 & 1.9 & $40.4 * * *$ & ns & ns \\
\hline Total Games & 32.4 & 27.8 & 30.0 & 41.0 & 23.3 & 31.3 & 37.8 & 25.3 & 31.7 & $18.1 * * *$ & $\mathrm{~ns}$ & $10.2 * *$ \\
\hline Other & .9 & .9 & .9 & .1 & .7 & .4 & 0.5 & 0.7 & 0.6 & ns & $4.3 *$ & ns \\
\hline
\end{tabular}

$*=\mathrm{p}<0.05 ; * *=\mathrm{p}<0.01 ; * * *=\mathrm{p}<0.001$

as $=$ approaching significance $-\mathrm{p}<0.10$

$\mathrm{ns}=$ not significant 
The Social context of school playground games

Table 2: Mean proportion of scans and ANOVA F values for types of behaviour produced by the children.

\begin{tabular}{|c|c|c|c|c|c|c|c|c|c|c|c|c|}
\hline & \multicolumn{3}{|c|}{ Time 1} & \multicolumn{3}{|c|}{ Time 2} & \multicolumn{3}{|c|}{ Overall } & \multicolumn{3}{|c|}{ ANOVA } \\
\hline & $\begin{array}{c}\text { Male } \\
\text { M }\end{array}$ & $\begin{array}{c}\text { Female } \\
\mathbf{M}\end{array}$ & $\begin{array}{c}\text { Total } \\
\mathbf{M}\end{array}$ & $\begin{array}{c}\text { Male } \\
\text { M }\end{array}$ & $\begin{array}{c}\text { Female } \\
\mathbf{M}\end{array}$ & $\begin{array}{c}\text { Total } \\
\mathbf{M}\end{array}$ & $\begin{array}{c}\text { Male } \\
\text { M }\end{array}$ & $\begin{array}{c}\text { Female } \\
\mathbf{M}\end{array}$ & $\begin{array}{c}\text { Total } \\
\mathbf{M}\end{array}$ & $\begin{array}{l}\text { Sex effect } \\
F=(1,117)\end{array}$ & $\begin{array}{c}\text { Time effect } \\
F=(1,117)\end{array}$ & $\begin{array}{l}\text { Sex x time } \\
F=(1,117)\end{array}$ \\
\hline Onlooking & 14.1 & 11.7 & 12.8 & 23.5 & 20.4 & 21.8 & 19.0 & 15.9 & 17.4 & $4.3^{*}$ & $72.6^{* * *}$ & ns \\
\hline Unoccupied & 5.1 & 5.4 & 5.3 & 5.3 & 5.6 & 5.4 & 4.8 & 5.5 & 5.2 & ns & ns & ns \\
\hline Disputing & 2.4 & 2.2 & 2.3 & 1.6 & 2.2 & 1.9 & 2.1 & 2.2 & 2.2 & ns & ns & ns \\
\hline Tease/taunt & .4 & .6 & .5 & 1.3 & .6 & .9 & 0.6 & 0.6 & 0.6 & ns & as & as \\
\hline R\&T play & 6.3 & 1.8 & 3.9 & 6.9 & 1.9 & 4.2 & 6.5 & 1.9 & 4.2 & $51.1 * * *$ & ns & ns \\
\hline Aggression & 1.8 & .4 & 1.1 & .8 & .2 & .5 & 1.1 & 0.3 & 0.7 & $8.0 * *$ & ns & ns \\
\hline Positive Affection & 4.6 & 7.5 & 6.2 & 3.2 & 5.4 & 4.4 & 3.8 & 6.5 & 5.2 & $10.1 * *$ & $6.4^{*}$ & ns \\
\hline Distress/ crying & .5 & .8 & .7 & .3 & .3 & .3 & 0.4 & 0.5 & 0.4 & ns & $8.3^{* *}$ & ns \\
\hline Disciplined & 2.3 & .3 & 1.2 & 1.8 & .5 & 1.1 & 2.0 & 0.4 & 1.2 & $10.4 * *$ & Ns & ns \\
\hline
\end{tabular}

$*=\mathrm{p}<0.05 ; * *=\mathrm{p}<0.01 ; * * *=\mathrm{p}<0.001$

as $=$ approaching significance $-\mathrm{p}<0.10$

ns $=$ not significant 
The Social context of school playground games

Table 3: Mean sizes, proportion of scans and ANOVA F values for the size and composition of children's social networks.

\begin{tabular}{|c|c|c|c|c|c|c|c|c|c|c|c|c|}
\hline & \multicolumn{3}{|c|}{ Time 1} & \multicolumn{3}{|c|}{ Time 2} & \multicolumn{3}{|c|}{ Overall } & \multicolumn{3}{|c|}{ ANOVA } \\
\hline & $\begin{array}{c}\text { Male } \\
\text { M }\end{array}$ & $\begin{array}{c}\text { Female } \\
\text { M }\end{array}$ & $\begin{array}{c}\text { Total } \\
\text { M }\end{array}$ & $\begin{array}{c}\text { Male } \\
\text { M }\end{array}$ & $\begin{array}{c}\text { Female } \\
\text { M }\end{array}$ & $\begin{array}{c}\text { Total } \\
\text { M }\end{array}$ & $\begin{array}{c}\text { Male } \\
\text { M }\end{array}$ & $\begin{array}{c}\text { Female } \\
\text { M }\end{array}$ & $\begin{array}{c}\text { Total } \\
\text { M }\end{array}$ & $\begin{array}{l}\text { Sex effect } \\
F=(1,117)\end{array}$ & $\begin{array}{c}\text { Time effect } \\
F=(1,117)\end{array}$ & $\begin{array}{l}\text { Sex } \times \text { time } \\
F=(1,117)\end{array}$ \\
\hline \multicolumn{13}{|l|}{ Active Network } \\
\hline M size & .83 & .84 & .84 & .86 & .87 & .87 & 0.8 & 0.9 & 0.8 & ns & ns & ns \\
\hline Mostly male & 88.2 & 11.0 & 47.1 & 86.1 & 11.3 & 45.0 & 86.7 & 11.2 & 49.0 & $1565.9 * * *$ & ns & ns \\
\hline Mixed sex & 1.1 & 2.5 & 1.9 & 2.5 & 2.6 & 2.5 & 1.9 & 2.6 & 2.3 & ns & ns & ns \\
\hline Mostly female & 10.7 & 86.5 & 51.0 & 11.4 & 86.1 & 52.4 & 11.4 & 86.2 & 48.8 & $1464.5^{* * *}$ & ns & ns \\
\hline Same age & 56.1 & 52.1 & 53.9 & 50.9 & 49.5 & 50.1 & 53.5 & 51.3 & 52.4 & ns & $6.8^{*}$ & $\mathrm{~ns}$ \\
\hline Mixed age & 6.9 & 11.9 & 9.6 & 8.7 & 10.4 & 9.6 & 7.8 & 10.9 & 9.3 & $5.3^{*}$ & ns & as \\
\hline Same ethnic group & 32.7 & 41.7 & 37.5 & 29.8 & 40.1 & 35.5 & 32.0 & 41.4 & 36.7 & $4.5^{*}$ & as & ns \\
\hline Mixed ethnic group & 30.2 & 22.1 & 25.9 & 29.8 & 19.8 & 24.3 & 29.2 & 20.1 & 25.0 & $4.7^{*}$ & ns & ns \\
\hline \multicolumn{13}{|l|}{ Game Network } \\
\hline M size & 4.07 & 2.82 & 3.41 & 4.65 & 3.26 & 3.89 & 4.4 & 3.0 & 3.7 & $59.0 * * *$ & $13.6^{* * *}$ & ns \\
\hline Mostly male & 87.1 & 10.3 & 46.2 & 84.8 & 9.8 & 43.6 & 85.7 & 10.1 & 48.0 & $1730.5 * * *$ & ns & ns \\
\hline Mixed sex & 5.4 & 6.5 & 6.0 & 5.9 & 5.5 & 5.7 & 5.7 & 5.9 & 5.8 & ns & ns & ns \\
\hline Mostly Female & 7.5 & 83.3 & 47.8 & 9.3 & 84.8 & 50.8 & 8.6 & 84 & 46.3 & $1521.6^{* * *}$ & ns & ns \\
\hline Same age & 70.4 & 61.5 & 65.7 & 68.9 & 62.6 & 65.4 & 69.5 & 62.5 & 66.1 & $4.2^{*}$ & ns & ns \\
\hline Mixed age & 19.7 & 25.6 & 22.9 & 22.6 & 26.3 & 24.6 & 21.7 & 25.4 & 23.5 & ns & ns & ns \\
\hline Same ethnic group & 31.6 & 49.4 & 41.1 & 29.1 & 47.8 & 39.4 & 31.1 & 49.5 & 40.2 & $8.5^{* *}$ & as & ns \\
\hline Mixed ethnic group & 58.4 & 37.6 & 47.3 & 62.5 & 41.2 & 50.8 & 60.0 & 38.2 & 49.4 & $12.8 * * *$ & $8.4 * *$ & ns \\
\hline
\end{tabular}

$*=\mathrm{p}<0.05 ; * *=\mathrm{p}<0.01 ; * * *=\mathrm{p}<0.001$

as $=$ approaching significance $-\mathrm{p}<0.10$

$\mathrm{ns}=$ not significant 